\title{
El rol de los elementos referenciales en la indexicalidad social*
}

\author{
Rafahel Jean Parintins Lima** \\ David Colodrón Mayordomo***
}

\begin{abstract}
Resumen
El objetivo de este artículo es explorar el rol de los elementos referenciales en la indexicalidad sociolingüística, concretamente de los elementos referenciales empleados en un programa televisivo brasileño llamado Manos e minas, cuya temática es la cultura rapera de la periferia urbana de la ciudad de San Pablo. El enfoque teórico utilizado comprende estudios sociolingüísticos y socio-cognitivistas. A través del análisis cualitativo del uso de jergas de valor referencial, comprobaremos cómo ese uso indexicaliza identidades sociales. Los resultados indican que los elementos referenciales son muy importantes para la indexicalidad social y deben ser valorados más allá que sólo como elementos de función semántica. Concluimos que es necesaria una ampliación de las nociones de referencialidad e indexicalidad, mejorando la comprensión de la indexicalidad semántica y pragmática, la relación entre los usos lingüísticos y la vida social y los mecanismos sociolingüísticos interaccionales que forman parte de las cogniciones sociales.
\end{abstract}

Palabras clave: referencialidad; indexicalidad; cognición social.

\section{The role of referential elements in social indexicality}

\begin{abstract}
The aim of this article is exploring the role of referential elements in sociolinguistic indexicality in a Brazilian TV program called Manos e Minas, which is about the hip hop culture of suburbia in São Paulo City. Our theoretical approach comprises sociolinguistic and social cognitivist studies. Through qualitative analysis of the use of referential slangs, we show how this use indexes social identities. Results indicate that referential elements are very important to social indexicality and must be valued as more than just elements with semantic function. We conclude that it is necessary an ampliation of referentiality and indexicality notions for a better comprehension of semantic and pragmatic indexicality, the relation among the linguistic uses, social life and interactional sociolinguistic mechanisms that take part in social cognitions.
\end{abstract}

Key words: indexicality; social cognition.

Recibido: 30-03-2013 Aceptado: 27-06-2013

* El proyecto de investigación É nóis na fita, coordinado por Anna Christina Bentes (IEL/UNICAMP, Brasil), tiene el apoyo de Fundação de Amparo à Pesquisa do Estado de São Paulo (FAPESP, proceso no. 2009/08369-8).

** Brasilero, Máster en Lingüística, Instituto de Estudios del Lenguaje, Universidad Estatal de Campinas (IEL/UNICAMP), São Paulo, Brasil. El autor tiene el apoyo de la Coordenação de Aperfeiçoamento de Pessoal de Nível Superior (CAPES), en forma de beca de investigación, rafahel. jean@gmail.com

*** Español, Máster en Lingüística Aplicada a la Enseñanza de Español como Lengua Extranjera, Universidad de Jaén, Andalucía, España, peplo58@yahoo.es 


\section{Introducción}

Van Dijk (2012) observa que, tradicionalmente, la indexicalidad es entendida como la propiedad semántica de expresiones deícticas limitada a la orientación espacial y temporal de los participantes de una situación comunicativa. Pero los trabajos de Peirce (1960) y de otros autores plantean un concepto socio-semiótico de indexicalidad. Es esta concepción la que exploraremos en el presente texto, con el objetivo de estudiar el rol de elementos referenciales en la indexicalidad.

En las siguientes secciones, exploraremos los conceptos de referencialidad e indexicalidad y sus roles en el discurso, en las identidades sociales y en las cogniciones sociales. Todo ello lo haremos a través del análisis discursivo del uso de expresiones jergáticas de función referencial en el programa televisivo brasileño Manos e Minas, cuya temática es la cultura rapera y suburbana de la ciudad de San Pablo (Brasil). Además, nuestro análisis no sólo pretende esclarecer nuestros presupuestos teóricos sino también el proceso indexical.

\section{Los elementos referenciales}

Tradicionalmente, los elementos referenciales eran considerados formas lingüísticas utilizadas para indicar o localizar entidades de y en el mundo. Esta definición se basa en la semántica. Los elementos referenciales entran en escena cuando se piensa en la relación entre las palabras y las cosas. Los elementos referenciales están, por lo tanto, en el centro de la filosofía del lenguaje. El paradigma saussureano, por ejemplo, plantea la noción de signo, que relaciona una imagen acústica (significante) con una imagen mental (significado). Los objetos del mundo a que esas imágenes hacen referencia fueron llamados extra-lingüísticos o referentes (Peirce, 1960).

Sin embargo, hoy se trabaja con la idea de que no hay univocidad entre signo y objeto, o entre elemento referencial y referente, cuando esos elementos son utilizados en el discurso. Es decir, que los significados son construidos y negociados socio-interactivamente en la misma situación comunicativa y la lengua se refiere justo a ellos. Pero esta forma de entender los elementos referenciales nos lleva a cuestionar la estabilidad de su referencialidad: ¿acaso un elemento referencial está siempre asociado al mismo referente? No siempre. Primero, porque el elemento referencial se asocia, en verdad, a una representación mental y dinámica 
de ese referente (Van Dijk, 2012). Segundo, porque, como los significados son construidos en la situación comunicativa, esa representación puede cambiarse con la negociación y construcción de los mismos. La referencialidad de estos elementos, por lo tanto, es más una cualidad pragmática que una direccionalidad semántica.

Según Errington (1985), los elementos referenciales son los más susceptibles de poseer relieve pragmático, es decir, de servir como fuertes identificadores de un grupo o una comunidad sociolingüística. Esa capacidad sociolingüística de identificar a un grupo o a una comunidad es llamada indexicalidad no referencial o social (Silverstein, 1976).

\section{Las indexicalidades}

La explicación de la sociolingüista Woolard (2008) es muy clarificadora para entender la indexicalidad:

Los usuarios de la lengua tienden a asociar formas lingüísticas específicas con tipos específicos de hablantes o contextos de habla (una afirmación básica de la sociolingüística variacionista). El significado derivado desde la contigüidad o asociación es conocido en la semiótica de C. S. Peirce (1960) (y otros) como indexicalidad. En el sistema de Silverstein, que se basa en la obra de Peirce, la indexicalidad de primer orden es el trabajo pre-ideológico, pero todavía semiótico, de la formación de estas asociaciones. Como Lesley Milroy señala, no sólo categorías sociales consagradas, como la clase, el género y la etnia, pueden ser indexadas lingüísticamente, sino también categorías locales, como la iglesia o la pertenencia a un grupo de iguales (2004: 167). Es decir, en la captura de este tipo de relaciones asociativas o indexicales de la vida social y del habla, los actores -tanto los analistas como los miembros de la comunidad- no sólo perciben, sino también, en cierto sentido, crean y modifican categorías de habla y de hablantes, así como tipos de variables sociolingüísticas. Si la indexicalidad de primer orden supone un acto semiótico de identificación, la indexicalidad de segundo orden trae la ideología para influir en la relación percibida. La indexicalidad de segundo orden de Silverstein supone el constructo cultural política y/o moralmente valorizado de la asociación indexical de primer 
orden con un contenido intencional o un significado. En este segundo nivel, los actores racionalizan, explican y, por lo tanto, de forma inevitable, naturalizan e ideologizan las asociaciones sociolingüísticas (relaciones indexicales) que se han registrado en el primer orden. (Woolard, 2008: 437) ${ }^{1}$

Dicho de otra forma, hay una indexicalidad clásica, que tiene una base semántica, que Silverstein (1976) llama también de indexicalidad referencial, donde se puede ubicar la deíxis. La indexicalidad no referencial está relacionada, por su parte, con la indexicalidad de primer orden, y es considerada no referencial porque no establece la relación entre lenguaje y objeto mundano, sino lenguaje y categoría social (clase, género, etc.). Por ejemplo, al ser escuchado con cierto dialecto, una persona es identificada como alguien que viene de cierta región geográfica del país.

Pero hasta aquí todavía persiste un proceso solamente semiótico y sólo se habla de indexicalidad de segundo orden cuando entra en escena la ideología. Esta ideologización de las asociaciones sociolingüísticas, esto es, de las relaciones indexicales de primer orden, es un componente de una cognición social que se manifiesta en el uso de la lengua. Una cognición social es, a su vez, el conjunto homogéneo de conocimientos compartidos sobre un objeto social (Van Dijk, 1989; 1997; 2008; 2012; Van Dijk \& Kintsch, 1983).

En vista de esto, vamos a analizar el uso de elementos referenciales en el programa Manos e Minas y observar el rol de esos usos como índices sociales.

1 "Language users everywhere tend to associate particular linguistic forms with specific kinds of speakers or contexts of speaking (a basic assumption of variationist sociolinguistics). Meaning derived in this way from contiguity or association is known in the semiotics of C. S. Peirce (1960) (and others) as indexicality. In Silverstein's system, which builds on Peirce's work, first order indexicality is the pre-ideological but still semiotic work of forming these associations. As Lesley Milroy points out, not only time-honored social categories such as class, gender, and ethnicity can be indexed linguistically, but also such local categories as church or peer group membership (2004: 167). That is, in picking such associative or indexical relations out of the flow of social life and talk, actors - both analysts and community members - do not simply perceive but actually in a sense create and re-create categories of speaking and speakers as well as types of sociolinguistic variables. If first-order indexicality involves a semiotic act of noticing, second-order indexicality brings ideology to bear on the relationship noticed. Silverstein's second-order indexicality involves the politically and/or morally loaded cultural construal of the first-order indexical association with an intentional content or meaning. At this second level, actors rationalize, explain, and thus inevitably naturalize and ideologize the sociolinguistic associations (indexical relations) that they have registered at the first order" (traducción nuestra). 


\section{El Programa Manos e Minas}

Los datos fueron obtenidos de un programa televisivo brasileño llamado Manos e Minas ("Chicos y Chicas"), cuya temática es la cultura rapera de la periferia urbana de la ciudad de San Pablo (Brasil). Este programa es televisado por el canal TV Cultura todos los miércoles a las $19 \mathrm{~h} 30^{\prime}$ y algunas de sus emisiones componen el corpus del Proyecto É nóis na fita ${ }^{2}$, cuyo objetivo es describir y analizar la manera por la que los procesos de formación de registros sociolingüísticos y de elaboración de estilos de grupos sociales se influyen mutuamente, se complementan y /o entran en conflicto (Bentes, 2009). Para nuestro análisis, hemos tomado las formas referenciales de tres emisiones del programa: las de los días 28 de marzo, 21 de junio y 23 de agosto de 2009.

\section{Elementos referenciales encontrados}

Es evidente que, en una interacción verbal, se pueden encontrar muchos elementos referenciales. Una noción que se relaciona con la de elementos referenciales es la de "ítem lexical". Su noción tradicional es entendida como un ítem no sintáctico, sin función conectora, una entidad gramatical abstracta y no pragmática. Los ítems lexicales son formas de organización, etiquetamiento y memorización de información lingüística. Son ítems lingüísticos de búsqueda susceptibles de ser activados (Di Felippo y Dias-Da-Silva, 2006). La forma en la que se organizan nos sirvió como criterio de organización de nuestros propios datos. Así pues, el estudio de las formas de referencia puede considerarse, muchas veces, de forma similar a la forma con que se trabajan las formas lexicales referenciales.

Los usos referenciales de nuestro análisis, de la misma forma que se hace para abstraer el ítem lexical, son considerados como la forma producida y abstraída de la flexión nominal (Basilio, 2003). Por ejemplo, menino (chico en portugués brasileño), lo consideramos del mismo uso para mejor organizar los datos, que menina (chica), porque la diferencia entre ellos reside solamente en el género (menino es masculino y menina es femenino). Manos (amigos) es el mismo ítem lexical que mano (amigo),

2 Proyecto "É nóis na fita": a formação de estilos e a elaboração de estilos no campo da cultura popular urbana paulista (FAPESP, proceso n. 2009/08369-8). 
porque la única diferencia entre ellos es solamente el número (manos en plural y mano en singular. Entre los elementos usados en nuestros datos separamos, en la Tabla 1, las siguientes expresiones jergáticas.

Tabla 1: Expresiones jergáticas como elementos referenciales

\begin{tabular}{ll}
\hline Elementos referenciales & $\begin{array}{c}\text { Significado o expresión aproximada } \\
\text { en español }\end{array}$ \\
\hline Bagulho & La cosa \\
\hline Cara, fera, mano, tio (zinho) & Tío \\
\hline Clima & Rollo, ambiente \\
\hline Galera, rapaziada & Pandilla, panda, mi gente \\
\hline Ganha-pão, trampo & Ganapán \\
\hline Grana & Pasta, plata \\
\hline Jogada & Jugada \\
\hline Lance, parada & Lance, chaparrón \\
\hline Meu irmão & Mi hermano, mi compadre \\
\hline Mina & Chica \\
\hline Pivete & Chico, chaval \\
\hline Ralação & En marcha \\
\hline Som & Sonido, ritmo, son \\
\hline
\end{tabular}

Mina es un elemento referencial de género femenino y aparece como una forma independiente de mano, que puede ser considerado su versión masculina. Pero no consideramos a ambos como manifestaciones del mismo ítem lexical mano porque uno no es la flexión del otro. Son, por lo tanto, ítems lexicales diferentes. Además, pusimos en una misma línea de la tabla los elementos con el mismo significado para facilitar la organización, pero se trata, como hemos dicho, de ítems lexicales diferentes. Y, por último, algunas formas lingüísticas no fueron consideradas como referenciales ya que, en el discurso, pueden perder ese valor de referencialidad y poseer una función interactiva, como muestra la Tabla 2. 
Tabla 2: Expresiones jergáticas no referenciales

\begin{tabular}{|c|c|}
\hline Formas lexicales nominales & $\begin{array}{c}\text { Función (interactiva) o expresión } \\
\text { aproximada en español con la } \\
\text { misma función }\end{array}$ \\
\hline $\begin{array}{l}\text { Cara, fera, mano, doido, } \\
\text { meu, meu irmão, véio }\end{array}$ & $\begin{array}{l}\text { “¡Che!”, “¡tío!”, “¡hermano!”, } \\
\text { “¡compadre!” (vocativo) }\end{array}$ \\
\hline Firmeza & $\begin{array}{l}\text { "Eso es" (función interactiva de } \\
\text { confirmación) }\end{array}$ \\
\hline Firmeza & $\begin{array}{l}\text { "Todo bien", "muy bien" (respuesta } \\
\text { a un saludo) }\end{array}$ \\
\hline Galera, rapaziada & $\begin{array}{l}\text { “¡Oye!”, “ieh”, “¡oye gente!”, } \\
\text { “ipeña!” }\end{array}$ \\
\hline Satisfação & $\begin{array}{l}\text { "Mucho gusto", "un placer" (saludo } \\
\text { de llegada o después de conocer a } \\
\text { alguien) }\end{array}$ \\
\hline
\end{tabular}

Hay dos funciones interactivas diferentes para firmeza. Por eso, pusimos este ítem en dos líneas diferentes de la Tabla 2. Además, como podemos observar en las Tablas 1 y 2, no todas las expresiones jergáticas con forma nominal poseen valor referencial.

Para Iglesias (2007) y Preti (1984), las jergas son conjuntos de formas lexicales que identifican grupos sociales: algunas son más propias del grupo que otras, que son más ampliamente usadas por personas de fuera del grupo. Esta capacidad de identificación social es lo que llamamos indexicalidad no referencial o de primer orden.

Las expresiones jergáticas seleccionadas aquí son, en general, muy usadas por los jóvenes brasileños, pero su uso, a veces, depende de factores dialectológicos (como el uso de véio, más propio de la región de San Pablo). Según Iglesias (2007: 8-9): “Sea cual fuere, el argot [la jerga] siempre es el resultado de la inmediatez de la situación comunicativa, que lleva a una persona a seleccionar entre diferentes registros lingüísticos el más apropiado para ese momento y para un interlocutor o interlocutores concretos". Así que las expresiones jergáticas no son usadas en el programa Manos e Minas como código secreto de un grupo, porque son bien comprendidas por todos los telespectadores brasileños 
que ven el programa. Son incluso usadas por muchos jóvenes que no viven en la periferia de las ciudades, pero su valor indexical todavía está muy relacionado con la periferia, y precisamente este valor es explotado por el programa, que tiene la periferia como temática.

\section{El uso de elementos referenciales y la indexicalidad de segundo orden}

Consideramos aquí el concepto de referencialidad para que se pueda comprender el rol de estos elementos en la construcción de identidades sociales. Esos elementos sólo son utilizados en el discurso con vistas a la elaboración socio-interactiva de los significados. Asimismo, la referencialidad puede ser complementada cognitivamente una vez que los elementos referenciales, en la interacción, no hagan referencia directa a objetos del mundo, sino a representaciones socio-cognitivas de esos objetos, representaciones construidas y negociadas sociointeractivamente (Van Dijk, 2012; Marcuschi, 2007). Así, por ejemplo, tenemos el siguiente pasaje del programa Manos e Minas, en la que el presentador del programa dice:

Manos e Minas promueve la primera batalla... de Djs... y vosotros vais a conocer... los escogidos... Tuvimos un grupo de jurados... que escogieron con mucha competencia... a los cuatro finalistas que están aquí en el plató de Manos e Minas... para competir entre ellos... y la cosa (bagulho) va a estar al rojo vivo... (Emisión de 21/06/2009)3

Desde el punto de vista estrictamente semántico, bagulho, traducido como "la cosa" en español, como se ha señalado en la Tabla 1, es un término referencial general. Por lo tanto, es usado cuando se sabe de lo que se habla, para que no se creen dudas. En este caso, se refiere a la "batalla de Djs". En portugués, otros elementos referenciales son igualmente generales, funcionando como un comodín referencial, con poca especificación: coisa, negócio ("cosa").

3 El texto original en portugués es el siguiente: “O Manos e Minas promove a primeira batalha... de DJs... e você vai conhecer... os escolhidos... nós tivemos um corpo de jurados... que escolheram com muita competência... os quatro finalistas que estão aqui no palco do Manos e Minas... pra duelá entre si... e o bagulho vai ser muito lôco...". 
Sin embargo, en el nivel de análisis de la indexicalidad de primer orden, bagulho es cargado de significado social, relacionado con el tipo particular de cultura comunicativa de los jóvenes. Es así que la referencialidad deja de ser sólo una cuestión estrictamente semántica. En este sentido, bagulho tiende a significar algo más en el contexto dado.

"Yo siempre he sido soñador y eso es lo que me mantiene vivo. Cuando yo era un chaval (pivete), mi sueño era ser jugador de fútbol" (Emisión de 23/08/2009)4

En el caso de pivete ${ }^{5}$, traducido como "chaval" o "chico" en español, tenemos un elemento referencial más restringido a ciertos grupos sociales. Así, este elemento es más propio de este grupo que sale en televisión, que es el de la periferia paulistana. En el nivel de análisis de la indexicalidad de segundo orden, esto es, considerando procesos ideológicos, el uso de este elemento referencial es más susceptible de sufrir restricciones de uso por parte de otros grupos sociales, por la existencia de una cognición social que lo trata con prejuicio sociolingüístico. Esa susceptibilidad es llamada por Errington (1985) relieve pragmático. A veces, ese término tiene incluso un valor ofensivo, pero éste no es el caso del pasaje.

Tratamientos similares de expresiones referenciales en el programa Manos e Minas pueden ser encontrados en Bentes y Ferrari (2011), pero más enfocado en las representaciones socio-cognitivas de la noción trabajo, empleo, etc. Como ya se ha dicho, el grueso de las expresiones referenciales que hemos seleccionado son generalmente conocidas por los brasileños. También tenemos dicho que tal circunstancia demuestra que el programa Manos e Minas está muy cargado de indexicalidad social, concretamente de una indexicalidad de identidad: la cultura de la periferia urbana brasileña, que tiene gustos propios como, por ejemplo, escuchar música rap.

Expresiones como "tamo aí na atividade" (algo como "estamos en marcha", con la función interactiva de estimular acciones en general y actividades grupales) se relaciona con la identidad rapera. Si agregamos a esa indexicalidad el elemento ideológico, obtenemos la llamada

4 "Eu sempre fui sonhador e é isso que me mantém vivo. Quando pivete, meu sonho era ser jogador de futebol".

5 Pivete es un término portugués. En español iría con " $b$ ", Pivete o Pebete, término coloquial Argentino y Paraguayo. (Nota del Editor) 
indexicalidad de segundo orden: ¿en qué contexto oigo esa expresión?, ¿a qué tipo de "actividad grupal" pienso que se refiere?, ¿tráfico de drogas?, ¿cantar raps?... Quien contesta son mis bases ideológicas. Esas bases son compartidas socialmente y este conocimiento social compartido forma parte de una cognición social.

\section{Conclusiones}

En este trabajo hemos revisado el concepto semántico de referencialidad, proponiendo una concepción interactiva y sociocognitiva de este fenómeno en el seno de un análisis de usos lingüísticos contextualizados. Según nuestro análisis, el discurso crea representaciones socio-cognitivas de identidades sociales propias a la cultura rapera de la periferia de la ciudad de San Pablo (y de grupos de otras partes de Brasil que se identifican con esa cultura). Estas representaciones sociocognitivas son percibidas a través del proceso de la indexicalidad no referencial o de primer orden, entendida no como la simple capacidad semántica de referirse a entidades mundanas, sino a representaciones socio-cognitivas de identidades sociales. Esas representaciones son influidas por la ideología promovida por la indexicalidad de segundo orden, que se refiere al grupo social en cuestión. Esta indexicalidad de segundo orden es la que principalmente produce lo que conocemos como prejuicio sociolingüístico: en nuestro caso, una actitud de rechazo al escuchar ciertos elementos referenciales de grupo y la disposición a no usarlos por personas ajenas a ese grupo.

Como hemos visto, las indexicalidades puedan ser procesos referenciales o no, pero también los elementos propiamente referenciales son objetos de esas indexicalidades no referenciales. De esta manera, la referencialidad semántica y la indexicalidad no referencial no son procesos meramente superpuestos, sino con ciertas interdependencias. Concretamente, en el presente artículo, el objeto tomado para relacionarlos son los elementos referenciales. $\mathrm{Y}$ estos resultados nos ayudan a comprender mejor no sólo los procesos lingüístico-cognitivos de las interacciones sociales, sino también el tipo de relación que se establece entre lenguaje y sociedad. 


\section{Referencias Bibliográficas}

Basílio, Margarida (2003). Teoria lexical (7 $7^{a}$ edición). São Paulo: Editora Ática.

Bentes, Anna Christina (2009). É nóis na fita: a formação de registros e a elaboração de estilos no campo da cultura popular urbana paulista. Projeto de Pesquisa-FAPESP.

Bentes, Anna Christina y FERRARI, Natália (2011). “E agora o assunto é trabalho: organização da experiência social, categorização e produção de sentidos no programa Manos e Minas". En Revista Diadorim/Revista de Estudos Linguísticos e Literários do Programa de PósGraduação em Letras Vernáculas da Universidade Federal do Rio de Janeiro (vol. 10), 75-93. Disponible en: <http:/ / www.revistadiadorim.letras.ufrj.br> [Consultado: 12/12/2012].

Di Felippo, Ariani y DIAS-DA-SILVA, Bento (2006). “Dos olhares sobre o léxico: diferenças e semelhanças". En B. C. DiasDa-Silva y B.N.O. Longo, (orgs). A construção de dicionários e bases de conhecimento lexical. Série Trilhas Lingüísticas 9, 169-185. Araraquara: Laboratório Editorial FCL/UNESP; y São Paulo: Cultura Acadêmica Editora. Disponible en: <http: / / www.geterm.ufscar.br/ariani/Dos_olhares_ sobre_o_lexico.pdf $>$. [Consultado: 15/11/2012].

Errington, J. Joseph (1985). "On the nature of the sociolinguistic sign: Describing the Javanese speech levels". En Elizabeth Mertz and Richard J. Parmentier (eds.) Semiotic Mediation. Orlando, Florida: Academic Press, 287310.

Iglesias, José Manoel (2007). Diccionario de argot español. Madrid: Alianza Editorial.

Marcuschi, Luiz Antonio (2007). Cognição, linguagem e práticas interacionais. Rio de Janeiro: Lucerna. 
Peirce, Charles Sanders (1960). Collected Papers. En 8 volúmenes. Editado por Charles Hartshorne, Paul Weiss y Arthur W. Burks. Cambridge, Massachusetts: Harvard University Press.

Preti, Dino (1984). A gíria e outros temas. São Paulo: Edusp.

Silverstein, Michael (1976). "Shifters, verbal categories and cultural description". En K. Basso y H. Selby (orgs.). Meaning in anthropology. Albuquerque: School of American Research, 11-57.

Van Dijk, Teun (1989). "Structures of discourse and structures of power". En J. A. Anderson (ed.). Communication Yearbook 12. Newbury Park, CA: Sage, 18-59.

. (1997). Discourse studies: a multidisciplinary introduction. En 2 volúmenes. London: Sage.

. (2008). Society in Discourse: how context controls text and talk. Cambridge University Press.

. (2012). Discurso e contexto: uma abordagem sociocognitiva. Traducción de Rodolfo Ilari. São Paulo: Cortez.

Van Dijk, Teun y Kintsch, Walter (1983). Strategies of discourse comprehension. New York: Academic Press, 1-19.

Woolard, Kathryn (2008). “Why dat now?: linguistic-anthropological contributions to the explanation of sociolinguistic icons and change". Journal of Sociolinguistics, vol. 12, issue 4. 432-452. 